\title{
Adopting a Circular Economy: Current Practices and Future Perspectives
}

\author{
Idiano D'Adamo
}

Department of Law and Economics, Unitelma Sapienza-University of Rome, Viale Regina Elena 295, 00161 Roma, Italy; idiano.dadamo@unitelmasapienza.it

Received: 4 December 2019; Accepted: 6 December 2019; Published: 9 December 2019

\begin{abstract}
All scientists, researchers, and citizens are involved in achieving sustainable goals. Their current actions contribute to writing a story for future generations, and interesting perspectives can be narrated based only on a great sense of social responsibility. The literature gives a great deal of attention to the models of a Circular Economy (CE). This topic is multidisciplinary and different sectors are involved in its development. This Special Issue aims to underline the relevance of the CE models in the scientific field and its applications in real contexts in order to achieve sustainability goals.
\end{abstract}

Keywords: circular economy; social sciences; sustainability

\section{Introduction}

The Circular Economy (CE) model is able to support sustainable development and has gained attention among policy makers, scholars, and practitioners (Ghisellini et al. 2016). The European Environment Agency has interpreted the $\mathrm{CE}$ as the core of a Green Economy perspective that extends the focus from waste and material use to human well-being and ecosystem resilience (see Figure 1) (European Environment Agency 2015). Transitioning to a CE cannot only be used to overlap the linear 'take, make, and dispose' economic model and the Ellen MacArthur Foundation identifies three principles in this regard (The Ellen MacArthur Foundation 2013):

i. "design out waste and pollution".

ii. "keep products and materials in use".

iii. "regenerate natural systems".

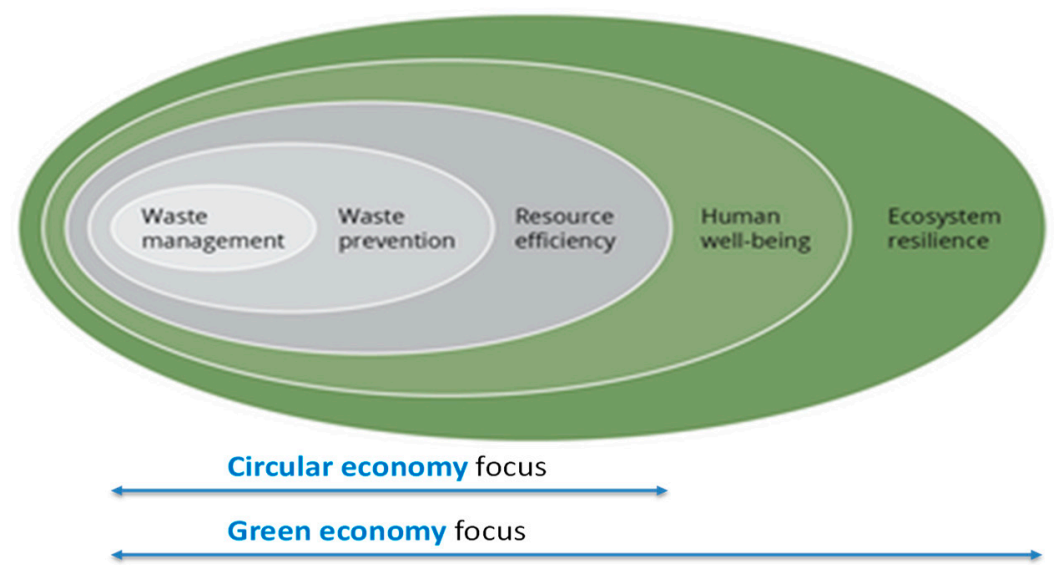

Figure 1. A circular economy and green economy (European Environment Agency 2015). 
The World Economic Forum in collaboration with several organizations, such as the Ellen MacArthur Foundation and World Resources Institute, has published a document called Platform for Accelerating the Circular Economy (PACE) in 2017 with the aim to adopt the principles of CE on the global scale. The waste created by a linear economy damages human health and the environment. Instead, waste that comes from several processes and is inserted into a circular economy provides "beneficial artifacts" for human use (Sikdar 2019). The importance of engineering considerations and design is considered to be vital in order to develop processes in which all parts of a material can be reused/recycled/recovered, thereby minimizing the amount of waste and its dangerousness if it would otherwise end up in landfill (Varbanov and Walmsley 2019).

The conceptualizing of the $\mathrm{CE}$ is provided by several works. Some authors provided the following observations. The first that $\mathrm{CE}$ is not always associated with the $3 \mathrm{R}$ framework (reduce, reuse, recycling) and generally with the waste hierarchy, but instead is often referred to only in the context of recycling. The second that $\mathrm{CE}$ is not only a change of the status quo, but also requires a change to a system perspective. The third suggests that the link between $\mathrm{CE}$ and sustainable development is weak, as economic prosperity followed by environmental quality are considered, while the impact on social equity is not analyzed. Finally, business models and consumers are evaluated as enablers of CE (Kirchherr et al. 2017).

CE aims to reduce both virgin material inputs and waste outputs by closing resource flow loops. Instead, the goals of sustainability are open-ended. However, the CE is defined as a condition for sustainability, and there are a wide range of complementary strategies that managers and policymakers can adopt (Geissdoerfer et al. 2017). In this way, the value of products and materials is maintained for as long as possible. Consequently, this approach assigns a relevance to material cycles characterized by high value and high quality (Amato et al. 2019). This provides an opportunity to develop an economic model in which both the production phase and the consumption phase are directed towards the protection of the environment (Korhonen et al. 2018). The direct relationship between the CE model and sustainable development is verified by quantitative analysis in which the profitability of the investment project and the reduction of the greenhouse gas emissions are both defined (D'Adamo et al. 2019).

This transition towards circularity requires us to measure its effects. It is possible to estimate a consistent number of indicators and they are specified in function of several criteria, as the levels of $\mathrm{CE}$ implementation, the $\mathrm{CE}$ loops, the performance, the perspective of circularity, and the degree of transversality (Saidani et al. 2019). The most commonly used methodologies to assess CE are Life Cycle Assessment, Life Cycle Inventory, and Life Cycle Impact Assessment followed by a Multi-Criteria Decision Making approach/fuzzy methods and Design for X (Sassanelli et al. 2019). The final aim is to demonstrate whether restoration and closed-loop product lifecycles are able to reduce waste, minimize the impact of toxic and harmful substances, keep the added value embedded in products and materials, and encourage the use of renewables. In addition, CE plans and targets must be characterized by a "human component", through training and building capacities: an integrative green human resource management framework is provided to support organizations (Jabbour et al. 2019).

\section{Form and Contents of the Thematic Issue}

Based on these concepts, this Special Issue tries to add new knowledge to the existing literature on the $\mathrm{CE}$. The final aim is to support the adoption of the CE paradigm in companies and organizations around the world. Due to the different sectors and perspectives related to the application of this model, the following papers propose several approaches.

The first work focuses its attention on the photovoltaic source, which represents a vital actor in a transition towards a low-carbon society. The study investigated both environmental and economic performances of photovoltaic systems in a market evaluating different policy scenarios. Subsidies provide a significant increase to profitability, and the reduction of greenhouse gas emissions is calculated as the difference between ones created by an energy mix based on fossil fuels and ones created by 
photovoltaic plants. Findings show the positive role of a renewable resource towards the link between sustainable development and CE application (D'Adamo 2018).

In a subsequent paper, economic growth was used as the dependent variable, in a function of independent variables, such as the productivity of resources, employment in the production of environmental goods, the recycling rate of municipal waste, market shares of innovative enterprises, and renewable energy uses. The analysis was conducted at the European Union level and the econometric model used demonstrates that the $\mathrm{CE}$ factors are relevant indicators of economic growth. Findings of this model permit us to quantify the contribution of each independent variable to the circularity with a primary role played by the productivity of resources (Busu 2019).

The third paper considers the quantitative status of employees in the Health and Social Care sector. Initially, it mentions that this sector fits the theory of unbalanced growth, in which there is has been decreasing productivity calculated based on the gross value added per employee. In the second part of the work, several European countries were examined in terms of their shares of employed persons in professions of this sector, providing specific country clusters. Also the Health and Social Care sector supports the development of circularity, thanks to the availability of technology and cooperation possibilities among all interested parties (Urbánková 2019).

Another work is based on a mixed data, involving continuous and categorical variables and it is aimed to evaluate the performance of solid waste management. This typology of waste represents an opportunity for municipal authorities to maximize the value of materials embedded in these waste and minimize the landfill use. A cluster analysis was implemented on these data. Findings of this work show the relationship of both waste generation and levels of $\mathrm{CO}_{2}$ emissions with recycling activities and awareness campaigns. Their role has been demonstrated be relevant towards the implementation of good practices of circularity (Caruso and Gattone 2019).

The fifth paper explores the potential development of a second-generation biorefinery in a touristic area trying to integrate waste management, renewable energy, and bio-product production. A Strengths, Weaknesses, Opportunities and Threats Analytical Network Process was used as a model. The results calculated the global priority of each factor and found that social acceptability occupies the first position, followed by excessive bureaucracy, green jobs, lack of long-term planning by governments, and lack of infrastructure technology. Circularity can be supported by some policy strategies, as e-government services, information campaigns, and public infrastructural investments (Falcone 2019).

A subsequent paper evaluates the principles of the $\mathrm{CE}$ applied to the manufacturing context. Specifically, a new business model for a ceramic tile manufacturer has been investigated evaluating the impact of an eco-design with a supply system of raw materials. The performance of the company was evaluated while considering the distance of the sources of supply from the factory and relative transport systems. In addition, a recycling process was proposed for the fired waste generated during the production phase. Findings show that eco-design associated with Industry 4.0 Internet of Things technologies can reach the equilibrium point between sustainability and CE (Garcia-Muiña et al. 2019).

Another work investigated the opportunities of the digital transformation of education on CE development to reach the goals of sustainability outcomes. Content analysis and the qualitative meta-synthesis of scientific works referred to digital education for sustainability were used as the methodology. Integrated findings were proposed for capital- and neo-capital-based multiple value formations, for emerging tools and technologies, for micro level interactions among actors and structures, and for macro level interactions among actors, structures, and technologies. As such, the learning of the value embedded in the $\mathrm{CE}$ transition requires customizable niches of learning preferences (Türkeli and Schophuizen 2019).

Finally, the last paper concerns the retail distribution and the transition from a linear to an incipient circular retail model. The framework used was based on the Retail Wheel Spins Theory and the Retail Life Cycle. This new circular model can be an opportunity for small entrepreneurs if they are able to intercept the production/selling of products based on a green-image and at the same time, consumers indicate growing interest towards this brand. The theoretical approach suggests that the $\mathrm{CE}$ transition can 
represent a solution to the crisis of the local market favoring the local image of the specific municipalities and provides a contrast to the power of the digital market (De-Juan-Vigaray and Seguí 2019).

\section{Concluding Remarks and Further Issues on the Research Agenda}

This Special Issue has demonstrated that the field of social sciences is interested in the development of CE models. Its development concerns several sectors and different authors have underlined this as circular economy concept moves towards the final aim of sustainability. The development of a closed loop cycle is a necessary condition to develop a CE model as an alternative to the linear model in order to maintain the value of products and materials for as long as possible. For this motive, the definition of the value must be demonstrated for both the environment and the economy. The presence of these analyses should be associated with the social dimension and the human component.

This editorial suggests some areas of research to investigate in the future:

- the current state of CE. Programs and initiatives in both developing and developed countries.

- future trends of CE. A program of change involving managers, consumers, and politicians.

- the analysis of CE policies. The role of subsidies, penalties, and taxes.

- an assessment of CE. The analysis of potential social opportunities, environmental improvements, and economic advantages.

- measurement of CE. The definition of indicators and the quantification of the circularity of a product.

- $\quad$ rethinking the concept of waste. Needs and opportunities.

- the transition towards a low carbon society. The relationship between the CE models and the use of renewable energies.

- the change on the production side (innovation, efficiency, and efficacy of firms) and on the demand side (the attitudes, behaviors, and practices of consumers).

A strong cooperation between social and technical profiles is a new challenge for all researchers. The End of Life of products attracts a lot of attention and the final output could be the production of technologies suitable for managing this waste and in doing so quantifying both economic and environmental benefits according to the principle of $\mathrm{CE}$.

Funding: This research received no external funding.

Conflicts of Interest: The author declares no conflict of interest.

\section{References}

Amato, Alessia, Alessandro Becci, Ionela Birloaga, Ida De Michelis, Francesco Ferella, Valentina Innocenzi, Nicolo Maria Ippolito, Pillar C. Gomez, Francesco Vegliò, and Francesca Beolchini. 2019. Sustainability analysis of innovative technologies for the rare earth elements recovery. Renewable and Sustainable Energy Reviews 106: 41-53. [CrossRef]

Busu, Mihail. 2019. Adopting Circular Economy at the European Union Level and Its Impact on Economic Growth. Social Sciences 8: 159. [CrossRef]

Caruso, Giulia, and Stefano Antonio Gattone. 2019. Waste Management Analysis in Developing Countries through Unsupervised Classification of Mixed Data. Social Sciences 8: 186. [CrossRef]

D'Adamo, Idiano. 2018. The Profitability of Residential Photovoltaic Systems. A New Scheme of Subsidies Based on the Price of $\mathrm{CO}_{2}$ in a Developed PV Market. Social Sciences 7: 148.

D'Adamo, Idiano, Pasquale Marcello Falcone, and Francesco Ferella. 2019. A socio-economic analysis of biomethane in the transport sector: The case of Italy. Waste Management 95: 102-15. [CrossRef] [PubMed]

De-Juan-Vigaray, Maria D., and Ana I. Espinosa Seguí. 2019. Retailing, Consumers, and Territory: Trends of an Incipient Circular Model. Social Sciences 8: 300. [CrossRef]

European Environment Agency. 2015. Circular Economy in Europe-Developing the Knowledge Base. Luxembourg: Publications Office of the European Union. 
Falcone, Pasquale Marcello. 2019. Tourism-Based Circular Economy in Salento (South Italy): A SWOT-ANP Analysis. Social Sciences 8: 216. [CrossRef]

Garcia-Muiña, Fernando E., Rocio González-Sánchez, Anna Maria Ferrari, Lucrezia Volpi, Martina Pini, Cristina Siligardi, and Davide Settembre-Blundo. 2019. Identifying the Equilibrium Point between Sustainability Goals and Circular Economy Practices in an Industry 4.0 Manufacturing Context Using Eco-Design. Social Sciences 8: 241.

Geissdoerfer, Martin, Paulo Savaget, Nancy Bocken, and Erik Jan Hultink. 2017. The Circular Economy-A new sustainability paradigm? Journal of Cleaner Production 143: 757-68. [CrossRef]

Ghisellini, Patrizia, Catia Cialani, and Sergio Ulgiati. 2016. A review on circular economy: The expected transition to a balanced interplay of environmental and economic systems. Journal of Cleaner Production 114: 11-32. [CrossRef]

Jabbour, Chiappetta, Charbel Jose, Josiph Sarkis, Ana Betriz Lopes de Sousa Jabbour, Douglas William Scott Renwick, Sanjay Kumar Singh, Oksana Grebinevych, Isak Kruglianskas, and Moacir Godinho Filho. 2019. Who is in charge? A review and a research agenda on the 'human side' of the circular economy. Journal of Cleaner Production 222: 793-801. [CrossRef]

Kirchherr, Julian, Denise Reike, and Marko Hekkert. 2017. Conceptualizing the circular economy: An analysis of 114 definitions. Resources Conservation and Recycling 127: 221-32. [CrossRef]

Korhonen, Jouni, Antero Honkasalo, and Jyri Seppälä. 2018. Circular Economy: The Concept and its Limitations. Ecological Economics 143: 37-46. [CrossRef]

Saidani, M., B. Yannou, Y. Leroy, F. Cluzel, and A. Kendall. 2019. A taxonomy of circular economy indicators. Journal of Cleaner Production 207: 542-59. [CrossRef]

Sassanelli, Claudio, Paolo Rosa, Roberto Rocca, and Sergio Terzi. 2019. Circular economy performance assessment methods: A systematic literature review. Journal of Cleaner Production 229: 440-53. [CrossRef]

Sikdar, Subhas. 2019. Circular economy: Is there anything new in this concept? Clean Technologies and Environmental Policy 21: 1173-75. [CrossRef]

The Ellen MacArthur Foundation. 2013. Towards the Circular Economy: Economic and Business Rationale for an Accelerated Transition. Available online: https://www.ellenmacarthurfoundation.org/assets/downloads/ publications/Ellen-MacArthur-Foundation-Towards-the-Circular-Economy-vol.1.pdf (accessed on 9 December 2019).

Türkeli, Serdar, and Martine Schophuizen. 2019. Decomposing the Complexity of Value: Integration of Digital Transformation of Education with Circular Economy Transition. Social Sciences 8: 243. [CrossRef]

Urbánková, Erika. 2019. The Development of the Health and Social Care Sector in the Regions of the Czech Republic in Comparison with other EU Countries. Social Sciences 8: 170. [CrossRef]

Varbanov, Petar Sabev, and Timothy Gordon Walmsley. 2019. Circular economy and engineering concepts for technology and policy development. Clean Technologies and Environmental Policy 21: 479-80. [CrossRef]

(C) 2019 by the author. Licensee MDPI, Basel, Switzerland. This article is an open access article distributed under the terms and conditions of the Creative Commons Attribution (CC BY) license (http://creativecommons.org/licenses/by/4.0/). 